\title{
DESIGNING SOCIAL SYSTEMS IN A CHANGING WORLD
}




\section{Contemporary Systems Thinking}

Series Editor: Robert L. Flood

University of Hull

Hull, United Kingdom

DESIGNING SOCIAL SYSTEMS IN A

CHANGING WORLD

Bela H. Banathy

LIBERATING SYSTEMS THEORY

Robert L. Flood

OPERATIONAL RESEARCH AND SYSTEMS

The Systemic Nature of Operational Research

Paul Keys

POWER, IDEOLOGY, AND CONTROL

John C. Oliga

SELF-PRODUCING SYSTEMS

Implications and Applications of Autopoiesis

John Mingers

SYSTEMS METHODOLOGY FOR THE

MANAGEMENT SCIENCES

Michael C. Jackson

A Continuation Order Plan is available for this series. A continuation order will bring delivery of each new volume immediately upon publication. Volumes are billed only upon actual shipment. For further information please contact the publisher. 


\section{DESIGNING SOCIAL SYSTEMS IN A CHANGING WORLD}

\section{Bela H. Banathy}

International Systems Institute

Carmel, California and

Saybrook Graduate School

San Francisco, California

Springer Science+Business Media, LLC 


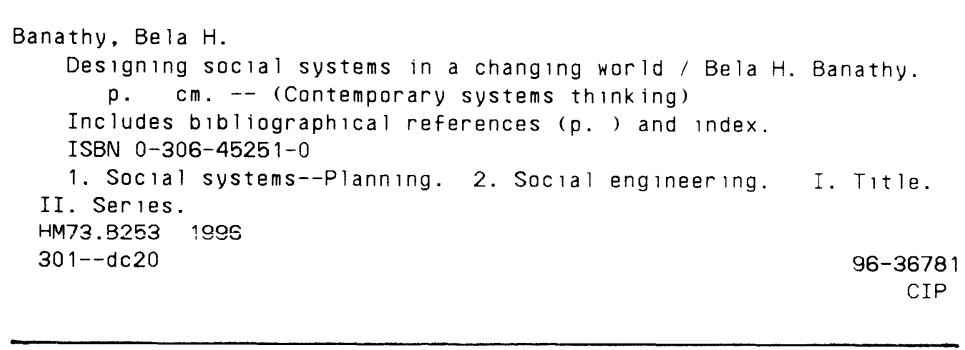

(C) Springer Science+Business Media New York 1996

Originally published by Plenum Press, New York 1996

Softcover reprint of the hardcover 1st edition 1996

\section{All rights reserved}

\section{1}

No part of this book may be reproduced, stored in a retrieval system, or transmitted in any form or by any means, electronic, mechanical, photocopying, microfilming, recording, or otherwise, without written permission from the Publisher 


\section{To Eva}

I must Create a System, or be enslav'd by another Man's;

I will not Reason and Compare; my business is to Create.

_William Blake, Jerusalem, pl. 10, 1.20 


\section{Preface}

What is presented in this work is based on a lifetime involvement in learning and exploring; in research, development, and applications; helping others to learn; and living and working in many organizational settings. An unwavering belief in human betterment has guided me through the decades, as with many others I have joined in creating resources, opportunities, and programs by which people, groups, organizations, and communities are enabled to develop and fulfill their individual and collective potentials and become the best they can.

In the course of the last decade, however, I have become increasingly convinced that even if people fully develop their potential, they cannot give direction to their lives, they cannot forge their destiny, they cannot take charge of their future-unless they also develop competence to take part directly and authentically in the design of the systems in which they live and work, and reclaim their right to do so. This is what true empowerment is about.

This book is about enabling such empowerment. It offers resources and programs by which individuals, groups, and organizations can learn to create a common ground, collectively define values and qualities they seek to realize, envision ideal images of a desired future, and bring those images to life by engaging in the disciplined inquiry of social systems design.

I am also convinced that this kind of empowerment, when learned and exercised by families, groups, organizations, and social and societal systems of all kinds, is the only hope we have to give direction to our evolution, to create a democracy that truly represents the aspiration and will of people, and to create a society about which all of us can feel good.

The ideas, the propositions, and the learning arrangements presented in this work have been influenced by many. What I have learned about systems and design inquiry I have learned with many others, in many ways, over several decades. And I am grateful to them. Nevertheless, I wish to acknowledge the very special help of a few friends who reviewed the manuscript and offered advice and guidance. The help of B. Antal Banathy, Aleco Christakis, Paul Hood, Lynn Jenks, Tad Frantz, and Gordon Rowland is much treasured and appreciated. Following their review, the seven of us spent a week in an intensive conversation at the 1995 International Conference of Social Systems Design, 
exploring the implications of the work for the further development of resources and programs in design learning and design applications. I also wish to thank Jean Sims for her editorial help.

I am most grateful to Ken Derham, Managing Director of Plenum Publishing Company, for embracing the idea proposed by this work, and thank his most capable editorial staff, Jeff Gilbert and his colleagues, who have worked on and guided the production of the book. 


\section{Contents}

1. Introduction ................................. 1

1.1. The Outline of the Work $\ldots \ldots \ldots \ldots \ldots \ldots \ldots \ldots \ldots$. 3

1.1.1. Part I: Understanding Design ............... 3

1.1.2. Part II: Adding Value to Systems Design and How System Design Adds Value to Society .......... 4

1.2. The Design of the Book ...................... 5

1.3. The Learning Strategy...................... 6

\section{Part I. Understanding Design}

2. What is Design? Why Do We Need It? ................. 11

2.1. Defining Design and Social Systems ............... 11

2.1.1. Definitions of Design .................. 11

2.1.2. Social Systems........................ 14

2.2. Comparison between Design and Other Modes of Inquiry ... 16

2.2.1. Systematic versus Systemic ................ 16

2.2.2. Design versus Science ................... 17

2.2.3. Design versus Art ................... 17

2.2.4. Design and Other Modes of Organizational Inquiry 18

2.3. Design as Decision-Oriented Disciplined Inquiry.......... 22

2.3.1. The Domains of Disciplined Inquiry .......... 22

2.3.2. Placing Design in the Context of Disciplined Inquiry 23

2.3.3. Types of Designed Systems ................ 25

2.4. The Nature of Design Problem Situations............ 26

2.4.1. Defining and Exploring the Meaning of Problems . . 26

2.4.2. The Characteristics of Problem Situations in Design 29

2.5. The Three Cultures: Science, Humanities, and Design ..... 33

2.5.1. Culture and the Culture of Design........... 33

2.5.2. Contrasting the Three Cultures............ 34

2.5.3. Why Do We Need a Design Culture?......... 35

2.5.4. Design Literacy..................... 36

2.5.5. Competence in Design ................ 36

2.5.6. The Prime Directive: Building a Design Culture ... 36

2.6. How People and Systems React to Change............ 37

2.6.1. Reactive Orientation: "Back to the Future"...... 38

2.6.2. The Inactive Style: "Don't Rock the Boat"...... 39 
2.6.3. The Preactivist Style: "Riding the Tide"........ 40

2.6.4. The Interactive Style: "Shooting the Rapids"..... 41

2.7. The Role of Design in a World of New Realities ......... 42

2.7.1. The New Realities.................... 42

2.7.2. Implications of the Emerged New Realities ...... 44

2.7.3. Systems Design: A New Intellectual Technology... 45

3. The Products and Processes of Design ................. 49

3.1. When Should We Engage in Design? What Is the Product of Design? .............................. 49

3.1.1. The Product of Design ................... 50

3.2. The Design Process...................... 55

3.2.1. Research Findings on the Nature of Design Activity 55

3.2.2. Models for Building Social Systems ........... 57

3.3. The Process of Transcending .................. 62

3.3.1. The Creation of a Framework that Offers an Option Field ............................. 63

3.3.2. Considering Options ................... 64

3.3.3. Implications of Using the Framework ......... 66

3.3.4. Generalizing the Example............... 67

3.4. Envisioning the Image of the New System ............ 68

3.4.1. The Meaning and Significance of Image......... 68

3.4.2. Sources in Creating Image ................ 69

3.5. Transformation by Design ...................... 71

3.5.1. The Design Architecture ................. 71

3.5.2. Design Dynamics ..................... 73

3.5.3. The Spirals and Their Operations through the Five Spaces ........................... 75

3.5.4. Modeling the Design Solution ............. 77

3.6. Three Systems Models that Portray Design Outcomes...... 78

3.6.1. Building Models of Social Systems ........... 78

3.6.2. A Description of the Three Models ........... 79

3.7. Developing a Plan for Bringing the Design to Life ........ 81

3.7.1. Ackoff's Means and Resources Planning ........ 82

3.7.2. Checkland's Implementation Approach ......... 83

3.7.3. Nadler's Approach ................... 83

3.7.4. Systems for Institutionalizing Change ......... 84

4. The Design Landscape ........................... 87

4.1. The Evolution of Design: The Historical Landscape ....... 87

4.1.1. The First Transformation: The Emergence of Homo Faber .......................... 88 
4.1.2. The Second Transformation: The Designer of Machines .......................... 89

4.1.3. The Third Transformation: The Age of Homo Gubernator...................... 90

4.2. The Universe of Design Inquiry. . . . . . . . . . . . 93

4.2.1. Design Inquiry.................... 93

4.2.2. Mapping the "Universe" of Design Inquiry ...... 96

4.3. Approaches to Systems Design and Social Change . . . . . . . 100

4.3.1. Generations of Design Approaches ............ 100

4.3.2. Total Systems Intervention (TSI) . . . . . . . . . 102

4.3.3. Guiding Deliberate Social Change............. 104

4.3.4. Breakthrough Thinking ................. 105

4.3.5. Rethinking Soft-Systems Methodology (SSM) . . . . 107

4.3.6. The Future-Search, Whole Systems Approach .... . 109

4.3.7. Interactive Management (IM) . . . . . . . . . 111

4.4. Initiating the Design Inquiry and Transcending the Existing State ................................ 113

4.4.1. Why Change? What Change Can Be Defined as Design? .......................... 113

4.4.2. Strategies and Methods Applicable to Transcend the System . . . . . . . . . . . . . . . . . . . . . . . 117

4.5. Approaches, Strategies, and Methods for Envisioning and Creating an Image of the Future System . . . . . . . . . . . . 124

4.5.1. Initial Exploration: Envisioning the Future . . . . . 125

4.5.2. Initial Exploration: Learning about New Realities.......................... 127

4.5.3. Initial Exploration: Making Boundary Judgments. . . 129

4.5.4. Initial Exploration: Creating the First Image of the System . . . . . . . . . . . . . . . . . 132

4.6. Approaches, Strategies, and Methods for Designing the Model of the Future System . . . . . . . . . . . . . . . . . . . . 134

4.6.1. The Definition of the System: What Are Its Purposes?... . . . . . . . . . . . . . . . . . . . . 135

4.6.2. What Are the Specific Functions that Must Be Carried Out? ....................... 138

4.6.3. Designing the Enabling Systems and the Systemic Environment ..................... 140

4.6.4. Presenting the Outcome of Design: Modeling the System . . . . . . . . . . . . . . . . . . . . . . . . 141

4.7. Group Techniques that Aid Design . . . . . . . . . . . 143

4.7.1. Group Techniques for Generating and Evaluating Ideas . . . . . . . . . . . . . . . . . . . . . . . . . 144

4.7.2. Assigning Roles and Responsibilities ......... 146 
4.7.3. Other Group Techniques. . . . . . . . . . . . . . 147

4.7.4. The "Cogniscope" System of Social Systems Design 149

\section{Part II. Adding Value to Systems Design and How Systems Design Adds Value to Society}

5. Design as a Multidimensional Inquiry . . . . . . . . . . . . 155

5.1. Systems Thinking . . . . . . . . . . . . . . . 155

5.1.1. Systems Thinking in Social Systems Inquiry ..... 156

5.1.2. The Evolution of Systems Thinking . . . . . . . 157

5.1.3. Systems Philosophers and Their Systems Thinking 160

5.2. Design Thinking ..................... 163

5.2.1. Systems Scholars' Ideas on Design Thinking ..... 164

5.2.2. Special Markers of Design Thinking .......... 167

5.2.3. Design Implications of the "New Physics"....... 168

5.3. Multiple Perspectives . . . . . . . . . . . . . . . 172

5.3.1. The Need for a Multiple-Perspectives Paradigm. . . 173

5.3.2. Using a Set of Interacting Perspectives ........ . 174

5.3.3. The Interaction and Integration of Multiple Perspectives . . . . . . . . . . . . . . . . . . . 175

5.3.4. Guidelines for the Use of Multiple Perspectives.... 176

5.4. The Ethics of Social Systems Design ... . . . . . . . . . . 179

5.4.1. Ethics Integrates Multiple Perspectives in Social Systems Design... . . . . . . . . . . . . . . . 179

5.4.2. Ethical Perspectives in Social Systems Inquiry..... 182

5.4.3. Ethics and Morality: An Evolutionary Perspective. . 183

5.4.4. Churchman: The Ethics of the Whole System .... . 186

5.4.5. Ethical Accounting ................. 187

5.5. The Design of the Ideal System . . . . . . . . . . . . . . 189

5.5.1. Ethics and the Ideal System . . . . . . . . . . 189

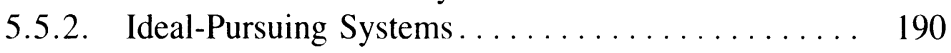

5.5.3. The Ideal Systems Concept . . . . . . . . . . . . . 191

5.5.4. Idealized Systems Design ... . . . . . . . . . . . . 192

5.5.5. Benefits of Engaging in Idealized Design ....... 193

5.5.6. Evolutionary Imperative of the Ideal Systems Design Approach...................... 193

5.5.7. Implications and Consequences of Ideal Systems Design . . . . . . . . . . . . . . . . . . . . . . . . . 194

5.6. Creativity in Systems Design . . . . . . . . . . . . . . . . . . . 197

5.6.1. Creativity: Definitions................. 196

5.6.2. Connecting Creativity with the Ideal Systems Design Approach. 
5.6.3. Exploring the Realms of Creativity . . . . . . . . . 199

5.6.4. Inner Conditions of Creativity ............. 202

5.6.5. Conditions of Fostering Creativity........... 203

5.6.6. Conditions and Forces that Block Creativity...... . 204

5.6.7. Misconceptions about Creativity ............ 205

5.6.8. The Significance and Power of Creativity....... 206

5.6.9. Implications for Systems Design ........... 206

5.6.10. Creativity in the Design Literature.......... 208

5.6.11. Exploring the Role of Creativity in the Course of

Design .......................... 210

5.7. Design as Conversation...................... 213

5.7.1. Dialogue as Social Discourse .............. 214

5.7.2. Generative and Strategic Dialogue........... 218

5.7.3. Design Conversation.................... 218

6. Getting Ready for Design ........................ 223

6.1. Who Should be the Designers? .................. 223

6.1.1. The Evolution of Design Approaches .......... 224

6.1.2. The Key Markers of the "Designing Within"

Approach ............................ 228

6.2. The Designing Community.................. 231

6.2.1. Authentic Communities ................ 232

6.2.2. Design Teams: The Core Units of a Designing Community ...................... 237

6.2.3. A Definition of an Authentic Community........ 239

6.3. Developing a Design Culture ................... 240

6.3.1. Design Culture and Its Implications.......... 241

6.3.2. Building a Design Culture: Conceptualization ..... 242

6.3.3. Building a Design Culture: Realization ......... 245

6.3.4. A Strategy for Realization ................. 246

6.4. The Systems Complex of Design................ 247

6.4.1. Defining the Systems of the Systems Complex of Design ............................. 250

6.5. Designing the Designing System .............. 254

6.5.1. System (A): The Genesis System. . . . . . . . . . . . 254

6.5.2. Creating the Designing System (B) ........... 258

6.5.3. Designing Systems (C) in the Systems Literature... 263

6.6. Coordinating Design Methods with System Types........ 265

6.6.1. Methodology and System Types ........... 266

6.6.2. A Map for the Characterization of System Types .. 268

6.6.3. Implications . ...................... 273

6.7. Designing the Design Inquiry................ 276

6.7.1. The System of Design Inquiry ............ 276 
6.7.2. Architecture for Designing the Design Inquiry System . . . . . . . . . . . . . . . . . . . . . 278

6.7.3. The Dynamics of the Inquiry ............ 281

7. Evaluation and Value Adding...................... 283

7.1. Misconceptions and Underconceptualization............ 283

7.1.1. Misconceptions ......................... 284

7.1.2. Underconceptualization.................. 286

7.2. Pitfalls in Systems Design ...................... 291

7.2.1. Selected Statements from the Design Literature ......................... 291

7.2.2. Pitfalls We Might Stumble into in the Course of Design ........................... 293

7.3. Approaches to Design Evaluation .................. 297

7.3.1. Exploration of the Design Literature ............ 297

7.3.2. An Image of a Comprehensive Design Evaluation System ......................... 302

7.4. Value and Qualities to Realize in our Design............ 304

7.4.1. Qualities to be Manifested ................. 305

7.4.2. Defining Desirable Qualities .............. 306

7.4.3. An Example of System-Specific Qualities ....... 312

7.5. From Evolutionary Consciousness to Conscious

Evolution .................................. 313

7.5.1. A Systems View of Evolution .............. 313

7.5.2. Conditions of Purposeful Evolution.......... 316

7.5.3. Evolutionary Competence Through Evolutionary Learning...................... 317

7.5.4. Creating Conditions for Evolutionary Learning ... . 320

7.6. Guided Evolution ........................... 322

7.6.1. Evolutionary Guidance ................ 323

7.6.2. A Tentative Definition of Evolutionary Guidance Systems ........................ 324

7.6.3. What If? An Example of an Evolutionary Guidance System .......................... 325

7.6.4. Reflection on the Example .............. 328

7.6.5. Creating Evolutionary Guidance Systems ........ 328

7.6.6. The Design of Evolutionary Guidance Systems ... . 329

7.7. Contemplating the Contribution of Design to the Creation of a New Societal Way of Life..................... 331

7.7.1. Emerging Images of Guided Societal Evolution.... 332

7.7.2. Emerging Images of Democracy ............ 337

7.7.3. Reflections: Looking Back and Looking Ahead.... 344 
8. The Journey Continues .......................... 349

8.1. The Design of a Journey.................... 349

8.1.1. Spiral One: Creative Synthesis of Core Ideas ..... . 350

8.1.2. Spiral Two: Reflection ................... 350

8.1.3. Spiral Three: Emergence of Creative Insights..... 350

8.1.4. Spiral Four: Search for New Knowledge ........ 351

8.1.5. Spiral Five: Another Spiral of Reflection/

Creation ......................... 351

8.1.6. Spiral Six: Design Applications ............ 351

8.1.7. Spiral Seven: New Learning and Creating New

Knowledge......................... 351

8.2. A Departing Thought $\ldots \ldots \ldots \ldots \ldots \ldots \ldots \ldots \ldots \ldots \ldots \ldots \ldots \ldots$

References ................................... 353

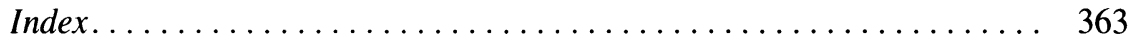

